\title{
Impact of sorghum grain processing on morphological characteristics of particles of wholegrain sorghum flour
}

\author{
María del Rosario ACQUISGRANA ${ }^{1,2}$, Laura Cecilia GOMEZ PAMIES ${ }^{1,2}$, Fernanda QUIROGA ${ }^{3,4}$, \\ Pablo Daniel RIBOTTA ${ }^{3,4}$, Elisa Inés BENÍTEZ ${ }^{1,2 *}$ (D)
}

\begin{abstract}
This work studies the physical characteristics of sorghum whole flour particles produced with grains reduced in tannins by hydrothermal treatment. Flours ground with two types of mills: a roll mill and a blade mill were used; grains were hydrated with a moisture content of $25 \%$. For this moisture the maximum yield was obtained. The effect of the grain moisture during the grinding was evaluated regarding the morphological characteristics, the granulometry and fractal dimension $\left(D_{f}\right)$ of particles. In all the analysed samples, bimodal size distribution curves were obtained. The treated samples showed medium size particles bigger than the samples without treatment. The samples without hydrothermal treatment presented particles with lower damage than the treated samples for both mills. The difference in $D_{f}$ between samples indicated more roughness for the samples with treatment. The proposed treatment could contribute to the development of sorghum whole flour with different properties for the development of gluten-free food.
\end{abstract}

Keywords: tannin; size distribution; fractal dimension.

Practical Application: Milling of whole sorghum hydrothermal treated affected flour particle characteristics. The understanding of the structural changes found will allow the development of products derived from sorghum flour.

\section{Introduction}

Sorghum (Sorghum bicolour (L.) Moench) is an important basic food eaten in warm and semi-arid regions of the world. It is rich in carbohydrates, fibre, vitamins, minerals and phytochemicals, including tannin, phenolic acids, anthocyanin and phytosterol (Girard \& Awika, 2018). These nutrients play an important role in the health and nutrition of human beings, especially in the case of persons who suffer from lifestyle disorders like celiac disease, diabetes and obesity (Pontieri et al., 2013). However, it is well known that tannins can reduce starch digestibility, which is why, different methodologies to reduce its concentration have been suggested. One of these methodologies is based on a hydrothermal treatment (Acquisgrana et al., 2016, 2019, 2020), which is the one that is going to be used in this work. Particle size reduction takes place as a preliminary step before the product development process (Duodu et al., 2002) which results in the rupture of the outer layer of the seed coat to expose the endosperm and its resulting fracture. Conventional size reduction machines for grain preparation in food processing include hammer mills, roll mills and friction mills (Mahasukhonthachat et al., 2010). They vary in the effective operation force and the amount of heat generation through friction during milling. These friction heat and mechanical energy could affect the molecular and structural properties of starch (damaged starch) and other components, which affects its functionality (Liu et al., 2014).
The damage of starch granules caused by milling increases the water retention capacity of flours (Acquisgrana et al., 2020) due to the increase of the levels of starch exposed to hydration and to enzymatic action.

Despite size differences, flour particles have almost the same shape, which could be characterized by a parameter called fractal dimension $\left(D_{f}\right)$ that serves to show the roughness of the particulate matter (Nayak et al., 2019). The fractal dimension shows the degree of divergence from smooth to rough surfaces. It varies from 2 (flat surfaces, softer particles) to 3 (completely rough surfaces) (Arzate-Vázquez et al., 2011; Nagai \& Yano, 1990). The $D_{f}$ is important since the separation of flour during the fractionation process depends on the characteristics of the surface and the shape of flour particles (Siliveru et al., 2016). If there are images of the particles, the Variogram method allows obtaining information about $D_{f}$ (Martínez Amezaga et al., 2018; Chen et al., 2018; Benítez et al., 2013). The mentioned method is based on variance $(\mathrm{V})$ calculation of the brightness level distribution of the sample surface image (Chen et al., 2018).

In many cases, the fractal analysis could be an additional fact, and it could be useful to give information about the characteristics of the tested preparations when specifying the reaction mechanism of aggregation and disintegration, when

${ }^{1}$ Laboratorio de Química Teórica y Experimental, Facultad Regional Resistencia, Universidad Tecnológica Nacional, Resistencia, Chaco, Argentina

${ }^{2}$ Instituto de Química Básica y Aplicada del Nordeste Argentino, Consejo Nacional de Investigaciones Científicas y Técnicas, Universidad Nacional del Nordeste, Corrientes,

${ }^{3}$ Instituto de Ciencia y Tecnología de Alimentos, Universidad Nacional de Córdoba, Córdoba, Argentina

${ }^{4}$ Facultad de Ciencias Exactas Física y Naturales, Cátedra de Química Aplicada, Universidad Nacional de Córdoba, Córdoba, Argentina

*Corresponding author: ebenitez@frre.utn.edu.ar 
optimizing the technological processes and when showing the correlation between microstructure, and its functional properties (Nayak et al., 2019). The accuracy of fractal analysis depends on many factors. In the case of the fractal analysis method based on bidimensional digital images, there are some aspects that could affect the process of analysis, such as the methods used to obtain binary images and the enlargement and the resolution of the image (Tang et al., 2010).

The methodology based on the $D_{f}$ determination was carried out by using images of particles obtained by SEM, and it has been very useful to explain the behaviour of colloidal aggregates in beer, according to Benítez et al. (2013) and fruit juice (Benítez et al., 2010), which could be applied to this study as well. Likewise, this methodology has been applied to fractal analysis to determine the roughness of the surface in hard and soft wheat flour (Siliveru et al., 2016). However, there is not enough information about the type of mill used and the moisture influence on the grain during milling, and their effect on the size, and the $D_{f}$ on the particles of sorghum flour.

In previous works, the effect on the yield performance of flours, using hydrated grains at different moisture levels and milled with two different mills, a roll mill and a blade mill (Acquisgrana et al., 2020), has been evaluated. It has been observed that at a grain moisture content of $25 \%$ with a blade mill (BM), a higher performance was obtained (61\%); however, studies on the size and shape of the particles when different grain moisture contents and a different type of mill were used, have not been carried out. Consequently, this work aims at characterizing particles of whole sorghum flour with a granulometry lower than $500 \mu \mathrm{m}$, obtained from whole grain reduced in tannin content through hydrothermal treatment.

According to Dayakar Rao et al. (2016), the milling process and the size of the particles are very important aspects to determine the quality of the products. These results could become a reference tool for further studies on the usefulness of the flours, regarding the characteristics they have, as well as to evaluate the influence of particles size and shape on food characteristics.

\section{Materials and methods}

\subsection{Whole sorghum flour production}

For this work, Sorghum bicolour (L.) Moench, variety TOB 60T, from the Experimental Agricultural Station-National Institute of Agricultural Technology (INTA) Argentina from the Northern East region of the province of Chaco was used. In order to evaluate the characteristics of flours particles, samples of whole flour without hydrothermal treatment, followed by roller (CS-RM) and blade (CS-MB) milling, were used as control samples. The samples, hydrothermally treated at $25 \%$ of moister, are called M-RM, if they were milled with a roller mill, and $\mathrm{M}-\mathrm{MB}$ if they were milled with a blade mill. The hydrothermal treatment for tannin reduction consisted in moistening the grains with a 1:2 ratio (sorghum grains/ water) during an hour at $75^{\circ} \mathrm{C}$, as mentioned in previous works (Acquisgrana et al., 2016, 2019). Afterwards, they are dried in an oven to reach moisture contents of $25 \%$. For this moisture the maximum yield was obtained previously (Acquisgrana et al., 2020). Then, the samples were milled with both mills and dried in an oven dryer at $50{ }^{\circ} \mathrm{C}$ for 24 hours. Finally, they were sifted using a standard mesh sieve No. 35 (A.S.T.M.), $500 \mu \mathrm{m}$. opening size.

\subsection{Particle size distribution}

The particle size distribution of whole sorghum flour was carried out using a laser diffraction particle analyser (LA-960, Horiba Instruments). Deionized water was used as a dispersing agent for all the samples. The measurements were carried out in duplicates. In order to calculate the volume percentages of the individual particles and of the packed particles, the Origin 6.0 (Origin Lab Corporation Northampton, MA, USA) was used. This software adjusts the data and calculates the total area under each peak of bimodal distribution. The volumes were converted to a number of particles using the average diameter obtained for each individual particle and the particulate matter.

\subsection{Determination of fractal dimension and average number of particles per particulate matter}

Fractal dimension $\left(D_{f}\right)$ was determined by the variogram method using the software FERImage (Szerakowska et al., 2018; Bianchi \& Bonetto, 2001). As regards fractals, the number of particles in each particulate matter, $\mathrm{N}$, is related to $D_{f}$ the radius of gyration $\left(R_{g}\right)$ and the average primary particle radius of the smallest particles, $\left(R_{p}\right)$, which forms the particulate matter (Equation 1) (Köylü et al., 1995; Sorensen \& Hageman, 2001):

$N=K_{g}\left(\frac{R_{g}}{R p}\right)^{D_{f}}$

where $K_{g}$ is a numerical constant, whose value depends on the properties of the system and it was experimentally determined from $D_{f}$ and the image projection data, as it is later explained. $R_{g}$ and $R_{p}$ could be obtained from the bimodal distribution of sizes (Benítez et al., 2010, Martínez Amezaga et al., 2018).

Furthermore, the number of particles in the particulate matter is related to its projected area, $A_{p}$, and the average transversal section of the smallest particle in the aggregate, $A_{I}$ (Individual particle projected area) (Equation 2), obtained from SEM images:

$$
\frac{A_{P}}{A_{I}}=K_{L}^{\frac{1}{w}}\left(\frac{R_{L}}{a}\right)^{\frac{D_{f}}{w}}
$$

where $K_{L}$ and the empirical constant $w$ were determined from a logarithmic graph of $A_{P} / A_{I}$ versus $\mathrm{R}_{\mathrm{L}} / a \cdot R_{L}$ (maximum radius) as adopted as $1 / 2 L$, where $L$ is the maximum longitude of the particulate matter and $a$ the average primary particle radius of the minimum particle which forms the particulate matter (Benítez et al. 2010).

The image processing software digital ImageJ 1.52a (digital image processing software of public domain, Java) developed by the National Institute of Health in USA) was used to determine $A_{p}, A_{P}, R_{L}$ and ${ }^{a}$. Considering the data obtained, $K_{g}$ was calculated from the following correlation (Benítez et al., 20 10; Köylü et al., 1995) (Equation 3): 


$$
\frac{K_{g}}{K_{L}}=\left(\frac{D_{f}+2}{D_{f}}\right)^{\frac{D_{f}}{2}}
$$

\subsection{Scanning electronic microscopy}

For a morphological characterization, the eight samples of flours were analysed through scanning electronic microscopy (SEM) with a SEM microscope (LEO, EVO 40, Carl Zeiss Microscopy Ltd., Cambridge, United Kingdom). Flour samples were treated with $2,5 \%$ glutaraldehyde in phosphate buffer $\mathrm{pH}=7.2$. Then, the samples were put on glass coverslips within polylysine film ( $\varepsilon$-poly-L-lysine, EPL) for an hour. Afterwards, the coverslips were washed with a buffer solution of dehydrated phosphate with $25 \%, 50 \%, 75 \%$ and $80 \%$ and three times with $100 \%$ solution of acetone and finally desiccated at critical point (Polaron E3000 CPD, U.S.A.) with acetone and $\mathrm{CO}_{2}$ as intermediate fluids. The samples were gold sputtered with an ion bombardment coat (Sputter Coater, Pelco 91000) and analysed by SEM (LEO, EVO 40, Cambridge, Eng.), at acceleration voltage of $10 \mathrm{KeV}$ (Benítez et al., 2013; Mercedes Lataza Rovaletti et al., 2014; Martínez Amezaga et al., 2018). Twenty images were considered for each flour at different increases 1.0, 2.0, 3.0, 4.0, 5.0 y 6.0 KX.

\subsection{Morphological characterization of particles and packets}

From the analysed SEM images, seventy packets were manually extracted for each sample of flour. Each packet was analysed by the Variogram method to determine $D_{f}$. The Variogram method is based on the calculation of the variance of $\mathrm{V}$ of the brightness level distribution of a sample surface image (Chen et al., 2018; Bianchi \& Bonetto, 2001). In order to obtain the $D_{\rho}$ the FERImage software was used (Bianchi \& Bonetto, 2001).

\subsection{Statistical analysis}

Data points were presented as the mean of the measured values. The data were subjected to an analysis of variance and the Turkey test at the 0.05 level of significance. The Infostat software (Di Rienzo et al., 2008) was used for the statistical analysis.

\section{Results and discussion}

\subsection{Particle size distribution}

The particle size distribution curves of the samples and the particle size parameter of the flours are shown in Figure 1 and Table 1, respectively.
A bimodal distribution was obtained and the diameters of particles varied between 10 and $1168 \mu \mathrm{m}$ in the treated samples $\mathrm{M}$ with both mills; whereas, the control samples ground with a roll mil (RM) (BM-RM) varied between 6 and $518 \mu \mathrm{m}$, and with a blade mill (BM) (BM-BM) between 7 and $891 \mu \mathrm{m}$. These results are within the evaluated ranges by Mahasukhonthachat et al. (2010); however, trimodal curves (5-50, 50-500 y 500-2000) have been observed by the mentioned authors. Bimodal curves have two maximum diameters, which correspond to individual starch granules sizes or to packed ones of smaller size and to endosperm fractions (packed ones of larger size).

Sorghum starch varies in size from 4 to $35 \mu \mathrm{m}$ (Zhu, 2014; Choi et al., 2008). Control samples presented a higher percentage of particles of smaller size as regards the treated flour for both mills (Table 2). The smaller particles are practically reduced to $50 \%$ in the case of flours treated with both mills compared to the samples without treatment, giving a higher percentage of particles of a bigger size.

The heterogeneity of particle size significantly affects the physicochemical properties of the flours when increasing the surface area by unit of volume. It can also increase the biodisponibility of macronutrients (carbohydrates, proteins) when increasing the digestion velocity, which would easily affect

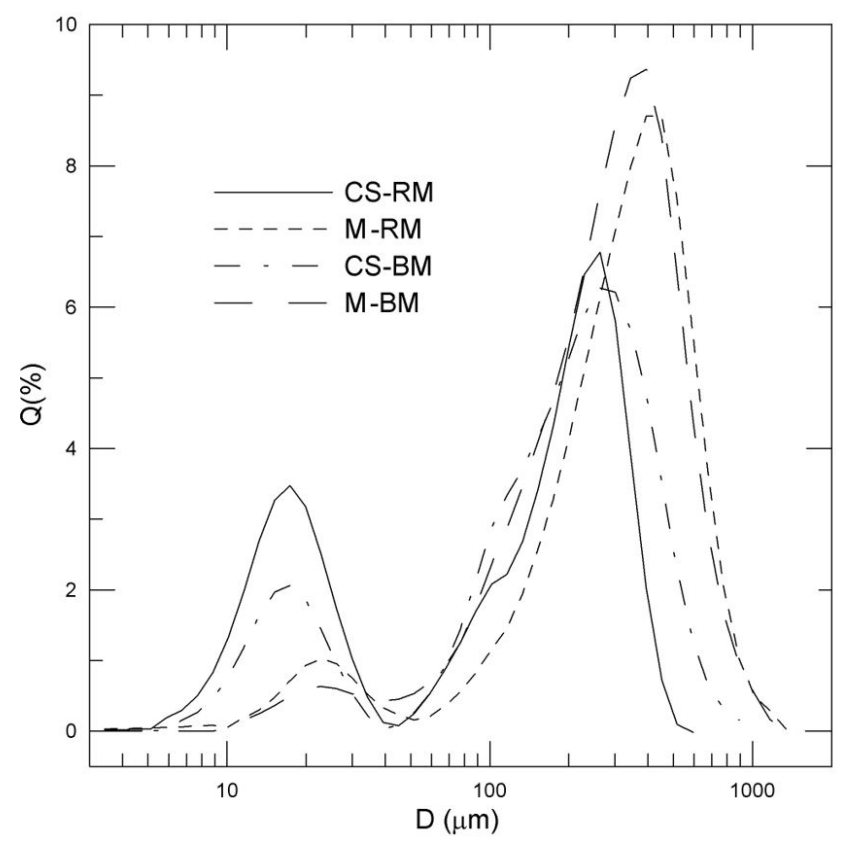

Figure 1. Particle size distribution for control sample (CS) and 25\% of Moisture (M) for roll mill (RM) and blade mill (BM).

Table 1. Parameters of particle size distribution of sorghum whole flour of Control Sample (CS) and treated flours at 25\% of moisture (M), ground with a Blade Mill (BM) and Roller Mill (RM).

\begin{tabular}{cccccccc}
\hline & Sample & $\mathrm{d}_{(10)}(\mu \mathrm{m})$ & $\mathrm{d}_{(50)}(\mu \mathrm{m})$ & $\mathrm{d}_{(90)}(\mu \mathrm{m})$ & Moda $(\mu \mathrm{m})$ & $\mathrm{d}_{[4,3]}(\mu \mathrm{m})$ & Span \\
\hline RM & $\mathbf{C S}$ & $13.70 \pm 0.43^{\mathrm{a}}$ & $111.94 \pm 2.14^{\mathrm{a}}$ & $283.77 \pm 0.09^{\mathrm{a}}$ & $229.12 \pm 14.25^{\mathrm{a}}$ & $130.63 \pm 1.06^{\mathrm{a}}$ & $2.43 \pm 0.05^{\mathrm{e}}$ \\
& $\mathbf{M}$ & $34.09 \pm 2.11^{\mathrm{b}, \mathrm{c}}$ & $250.17 \pm 3.71^{\mathrm{c}}$ & $534.41 \pm 13.38^{\mathrm{c}, \mathrm{d}}$ & $344.49 \pm 25.89^{\mathrm{b}}$ & $276.85 \pm 6.26^{\mathrm{c}}$ & $2.00 \pm 0.02^{\mathrm{c}}$ \\
BM & $\mathbf{C S}$ & $17.33 \pm 0.98^{\mathrm{a}}$ & $166.97 \pm 1.76^{\mathrm{b}}$ & $400.56 \pm 2.04^{\mathrm{b}}$ & $245.91 \pm 0.18^{\mathrm{a}}$ & $193.78 \pm 1.01^{\mathrm{b}}$ & $2.30 \pm 0.04^{\mathrm{d}}$ \\
& $\mathbf{M}$ & $46.58 \pm 0.62^{\mathrm{c}}$ & $258.65 \pm 1.01^{\mathrm{c}, \mathrm{d}}$ & $555.43 \pm 2.12^{\mathrm{c}, \mathrm{d}}$ & $369.35 \pm 0.27^{\mathrm{b}}$ & $286.95 \pm 0.83^{\mathrm{c}}$ & $1.97 \pm 0.00^{\mathrm{c}}$ \\
\hline
\end{tabular}

The means with different letters, within the same column, indicate significant differences between the samples $(\mathrm{p}<0.05)$. 
Table 2. Medium diameter, \% in volume and area under the curve of Control Sample (CS) and treated flours at 25\% of moisture (M), ground with a Blade Mill (BM) and Roller Mill (RM), obtained from the adjustment of the size distribution curves with the Origin software.

\begin{tabular}{|c|c|c|c|c|c|}
\hline & Sample & & $\bar{D}(\mu \mathrm{m})$ & Volumen (\%) & Area under the curve \\
\hline \multirow[t]{4}{*}{ RM } & CS & Individual particles & $18.5 \pm 0.2^{\mathrm{a}}$ & 3.36 & $53 \pm 1^{\mathrm{a}}$ \\
\hline & & packed particles & $184 \pm 4$ & 96.64 & $1523 \pm 29$ \\
\hline & $\mathbf{M}$ & Individual particles & $24.0 \pm 0.3^{b, c}$ & 0.85 & $28 \pm 2^{\mathrm{c}, \mathrm{d}}$ \\
\hline & & packed particles & $389 \pm 89$ & 99.15 & $3217 \pm 329$ \\
\hline \multirow[t]{4}{*}{$\mathbf{B M}$} & CS & Individual particles & $18,3 \pm 0.1^{\mathrm{a}}$ & 1.37 & $30.3 \pm 0.6^{\mathrm{a}}$ \\
\hline & & packed particles & $297 \pm 7$ & 98.63 & $2182 \pm 99$ \\
\hline & $\mathbf{M}$ & Individual particles & $23.8 \pm 0.4^{\mathrm{b}, \mathrm{c}}$ & 0.58 & $20 \pm 2^{\mathrm{c}, \mathrm{d}}$ \\
\hline & & packed particles & $411 \pm 7$ & 99.42 & $3501 \pm 274$ \\
\hline
\end{tabular}

The means with different letters, within the same column, indicate significant differences between the samples $(p<0.05)$.

human nutrition. The starch composition, the gelatinization and paste properties, the susceptibility of enzymes, the crystallinity, swelling and solubility are also affected by the granules size.

In the size distribution, the mean value is calculated in a similar way the average concept is. The laser diffraction results are reported on a volume basis, which is why, the volume mean can be used to define the central point, even though the median is more frequently used than the mean when this technique is used. In the presentation of the data, the mean is expressed as $\mathrm{d}_{[4,3]}$. The results of $\mathrm{d}_{[4,3]}$ were in accordance with those stated by Mahasukhonthachat et al. (2010) . It is observed that the samples without treatment show lower mean values than the treated samples do, being the roll mill value lower. There are significant differences compared to the blade mill.

The mode is the highest peak in the distribution. The mode represents the particle size (or size range) most commonly found in the distribution. The mode is not often used, but it could be descriptive, particularly if there is a peak in the distribution. Therefore, the modes are useful to describe the mid-point of the different peaks. In the distributions obtained, it is observed that the samples without treatment (for both mills) show similar values without significant differences, and that they increase in size with a moisture content of $25 \%$.

The D50, the medium, has been defined as the diameter where half of the population lies below this value. Likewise, $90 \%$ of the distribution lies below D 90 , and $10 \%$ of the population lies below D10. Thus, it could be considered that the medium (D50) shows a similar behaviour to the mean $\mathrm{d}[4,3]$ or to the mode. The analysis of D10 and D90 values shows a bimodal behaviour, which has lower values for both mills in the case of samples without treatment; a significant increase of smaller particles (D10) with moisture content increase is observed, being the bigger particles the ones ground with the BM, compared to those ones ground with the RM. Besides, a swelling of the particles occurs, as well as in the case of bigger samples.

One of the common values used for laser diffraction results is the span (Horiba manual) (Equation 4)

$\operatorname{Span}=\frac{D_{90}-D_{10}}{D_{50}}$
It is observed that the span value decreases with moisture content increase. Figure 1 and Table 2 show the values obtained from the adjustment of the size distribution curves with the Origin software used to calculate the areas under the curve. The decrease in the span added to the reduction of the area under the curve, Table 2, indicates a swelling and a probable rupture of the starch granules with the increase of moisture content for each mill, which causes a reduction in the amount of smaller particles. It does not occur the same with bigger particles; an increase in the area is observed when moisture content increases. This would indicate a swelling of the packets.

According to the results presented, it could be observed that both, the size and the flour particle distribution, are affected by the grain hydration in the grinding process and by the type of mill used.

\subsection{Scanning Electronic Microscopy (SEM)}

In Figure 2, SEM images of flours with and without treatment are shown. The diversity of irregular forms with a prevalence of spherical and polyhedral forms, typical of starch granules, is observed. They are packets formed from protein matrix-starch granules breakdown and cellular components. The structures of whole flour particles, such as more free starch granules for both mills, which could be part of the floury endosperm, can be highlighted in the images of flours without treatment (Figure 2a and c), whereas in the treated flours (Figure 2b and d) a higher proportion of packed structures, which could correspond to the corneal endosperm, can be observed. That is to say that whole grain conditioning to different moisture levels could help to break down or free the corneal endosperm structure; however, their sizes could be bigger than those of the samples without treatment, as it was previously observed.

Previous works (Acquisgrana et al., 2019) report that the treated samples for both mills, have a greater water retention capacity compared to the samples without treatment, which could be due to the starch damage during the milling process (Dayakar Rao et al., 2016), which has the potential to increase water absorption. This greater water absorption is particularly beneficial in the preparation of gluten-free cookies, since its effect would be similar to the addition of hydrocolloids that in previous studies have been responsible for greater hardness and 
fracturability, two attributes desired in these types of products (Shahzad et al.,2018).

The particles and packets damages could be observed in SEM images. The ground samples with BM show differences in the shape appearance of grains. In the samples without treatment, packed starch granules, as if they have been cut in random directions, of great surface and with well-defined starch granules in some cases and damaged ones in other cases, could be observed. Likewise, free starch granules of different shapes: spherical, oval, irregularly polyhedral, and some granules with rough appearance, could also be observed.

Nevertheless, the treated samples, compared to the samples without treatment, show packed particles with a damaged appearance, as if they have been crushed, where starch granules cannot be distinctly differentiated.
Regarding the RM, in the case of flour without treatment, freer starches of irregularly polyhedral and spherical shape are observed. The variation regarding their size, shape and surface could be attributed to the type of cuts made by the mill, the percentage of floury and corneal starch of the grain, the granule moisture, etc. The flours treated with the RM have similar characteristics to the ones ground with the BM.

\subsection{Fractal dimension}

Table 3 shows the results of $D f$ average of the packed particles which have been taken from SEM images. In the case of BM, there have not been significant differences among the samples. However, with the MR, there has been a significant difference $(\mathrm{p}<0.05)$ for the samples $\mathrm{M}-\mathrm{RM}$, resulting $2.53 \pm 0.01$ compared to $2.50 \pm 0.01$ for the sample CS-MR, which suggests that the
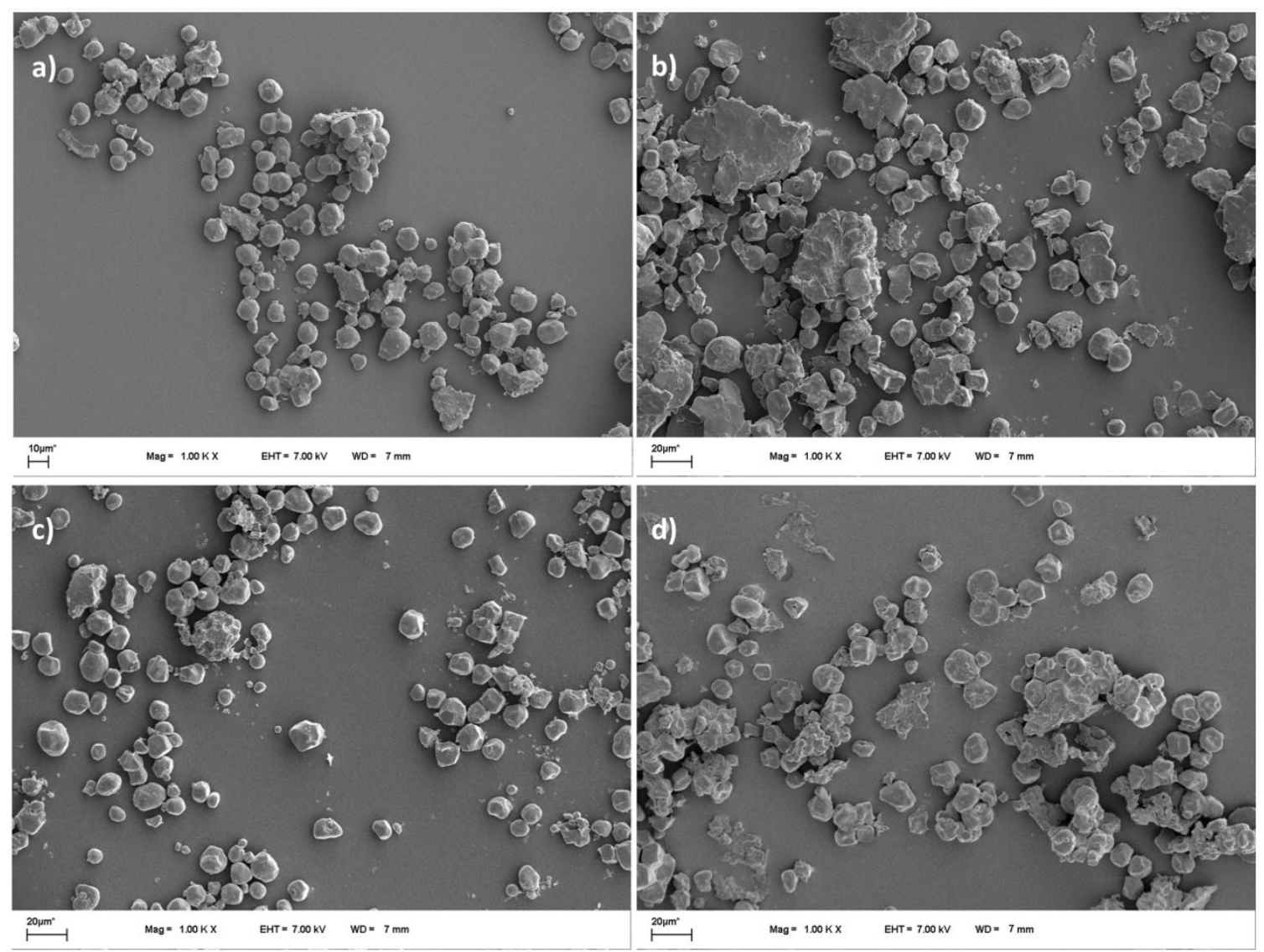

Figure 2. SEM images of (a) control sample ground with a blade mill (CS-BM); (b) treated flour at 25\% of moisture ground with a blade mill (M-BM); (c) control sample ground with a roller mill (CS-RM); (d) treated flour at 25\% of moisture ground with a roller mill (M-RM), all of them with an increase of $1.00 \mathrm{KX}$. Scale $20 \mu \mathrm{m}=63$ pixels.

Table 3. Fractal dimension, characteristics parameters of projected area and particle average number per aggregate of Control Sample (CS) and treated flours at $25 \%$ of moisture (M), ground with a Blade Mill (BM) and Roller Mill (RM).

\begin{tabular}{|c|c|c|c|c|c|c|}
\hline & Sample & $D_{f}$ & $\mathrm{w}$ & $\mathrm{KL}$ & $\mathrm{Kg}$ & $\bar{N}$ \\
\hline \multirow[t]{2}{*}{$\mathbf{R M}$} & CS & $2.50 \pm 0.01^{\mathrm{a}}$ & 2.59 & 1.72 & 3.58 & 847 \\
\hline & M & $2.53 \pm 0.01^{\mathrm{a}}$ & 2.12 & 1.02 & 2.12 & 663 \\
\hline \multirow[t]{2}{*}{ BM } & CS & $2.53 \pm 0.01^{b}$ & 2.73 & 1.48 & 3.10 & 3490 \\
\hline & $\mathbf{M}$ & $2.54 \pm 0.01^{\mathrm{b}}$ & 2.54 & 0.81 & 1.69 & 2345 \\
\hline
\end{tabular}

The means with different letters in the same column indicate significant differences between samples $(\mathrm{p}<0.05)$; KL= numerical constant dependent on the maximum length adopted ( $\mathrm{L}$ ). 
line border of packets could be more irregular for the sample M-RM. According to Nagai \& Yano (1990), the higher $D_{f}$ values show more roughness and a more irregular surface.

\subsection{Average number of particles per packet}

In Table 3, the results of the average particle number per packets of flour samples, calculated by Equation 1, are shown. The mean values, obtained by the adjustment of distribution curve from the Origen Software, were used for article number calculations. A higher number of particles per packet in the case of the samples ground with BM compared to the ones ground with RM is observed. In Figure 3, one of the obtained correlations, for example for the control sample ground with a BM, can be observed. The correlations were carried out applying the double logarithm to Equation 1. The values reported in Table 3 arise from the slope and intercept at the origin. A decrease in the number of particles per packet, with an increase in the moisture level is observed. However, a decrease in size is not observed, a fact that would imply a higher swelling of the particles.

The rupture of some starch granules could have probably occurred, with a subsequent reduction of particle number. The $\mathrm{w}, \mathrm{K}_{\mathrm{L}}$ and $\mathrm{Kg}$ values are shape factors that, as well as fractal dimension, would indicate that particles are far from being spherical in shape. From the values obtained, it is observed that these parameters decrease as the moister level increases, and that there is not any significant difference between mills. The change in the surface roughness could be associated to a higher swelling and the loss of structure of the packets. These data are based on thermal properties data previously obtained, in which it is postulated that there could be a partial gelatinization of starch during the moisture increase treatment, the drying and milling treatments.

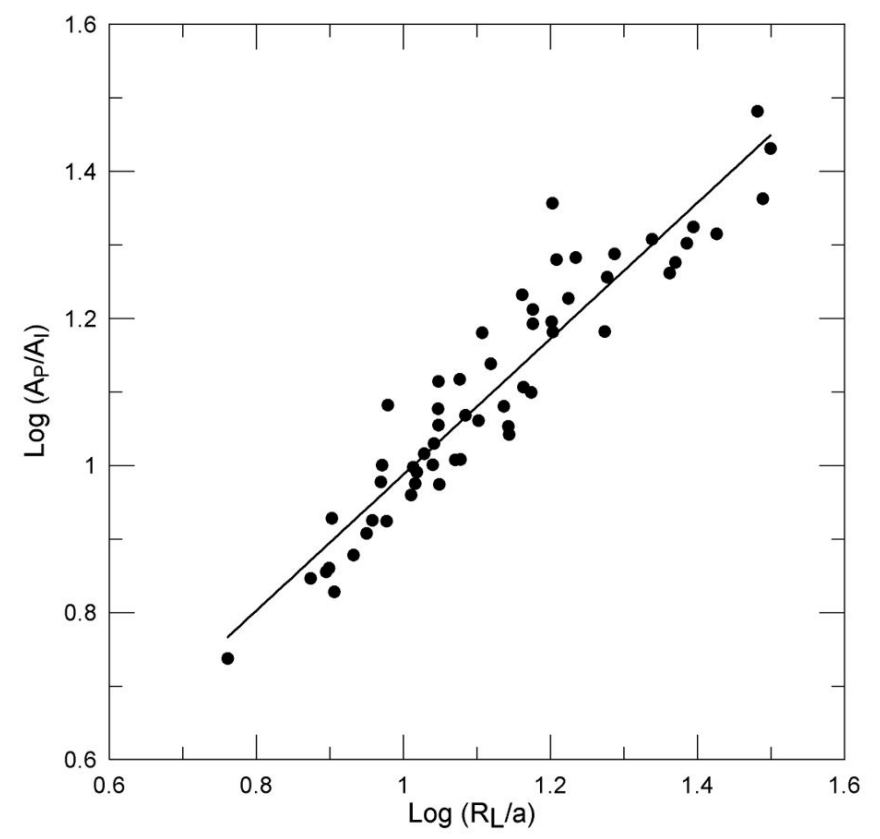

Figure 3. Correlation between $\log \left(\mathrm{R}_{\mathrm{I}} / \mathrm{a}\right)$ and $\log \left(\mathrm{A}_{\mathrm{P}} / \mathrm{A}_{\mathrm{I}}\right)$ for control sample ground with blade mill (CS-BM).

\section{Conclusions}

This work confirmed that the tannin extraction method together with the moisture content of whole grains for further grinding in a blade mill and in a roll mill affected the characteristics of whole flour particles causing significant changes in the typical parameters studies in size distribution, compared to flours without treatment. Bimodal curves, with two sizes of particles, where the types of mills and the moisture content of grain significantly modified the perceptual proportions of the treated samples, compared to the flours without treatment, were obtained in all the studied cases. Likewise, structural changes produced by moisture content variations and types of grinding of sorghum grains could be seen through micrography analysis. The study with SEM images showed, on the one hand, the granules of the floury endosperm in their most free and spherical shapes, and on the other hand, the packed granules that could belong to the corneal endosperm. This presented different shapes, sizes and damages due to the non-uniform fragmentation of the starch protein matrix of the sorghum grain endosperm and the type of mill used.

The granular appearance of the flours showed differences between flours with and without treatment, which causes that physicochemical and functional properties could differ.

Finally, packets of granules were characterized by the fractal dimension study, and it was determined that they have rough surfaces. Furthermore, significant differences in the average particle number per packets in the samples ground in roll and blade mills were observed.

The results obtained from the characterization of whole flour could contribute, together with other studies, to the development of sorghum whole flour with the aim of industrializing this cereal in this region.

\section{Acknowledgements}

The authors acknowledge Universidad Tecnológica Nacional - Facultad Regional Resistencia, for helping them publish the research topics that are being developed by the research team of Experimental Theoretical Chemistry (QuiTEx). They also thank UTN and Consejo Nacional de Investigaciones Cientìficas y Técnicas (CONICET) for financial support. They would also like to acknowledge Instituto Superior de Investigación, Desarrollo y Servicios en Alimentos (ISIDSA) de la Universidad Nacional de Córdoba for their cooperation to this research.

\section{References}

Acquisgrana, M. D. R., Pamies, L. C. G., \& Benítez, E. I. (2019). Hydrothermal treatment to remove tannins in wholegrains sorghum, milled grains and flour. Food Science and Nutrition Studies, 3(4), 122-132. http://dx.doi.org/10.22158/fsns.v3n4p122.

Acquisgrana, M. R., Benítez, E. I., Gomez Pamies, L. C., Sosa, G. L., Peruchena, N. M., \& Lozano, J. E. (2016). Total polyphenol extraction from red sorghum grain and effects on the morphological structure of starch granules. International Journal of Food Science \& Technology, 51(10), 2151-2156. http://dx.doi.org/10.1111/ijfs.13194. 
Acquisgrana, M. R., Gomez Pamies, L. C., Martinez Amezaga, N. M. J., Quiroga, F., Ribotta, P. D., \& Benítez, E. I. (2020). Impact of moisture and grinding on yield, physical, chemical and thermal properties of wholegrain flour obtained from hydrothermally treated sorghum grains (2020). International Journal of Food Science \& Technology, 55(7), 2901-2909. http://dx.doi.org/10.1111/ijfs.14548.

Arzate-Vázquez, I., Chanona-Pérez, J. J., Perea-Flores, M. J., Calderón Domínguez, G., Moreno-Armendáriz, M. A., Calvo, H., GodoyCalderón, S., Quevedo, R., \& Gutiérrez-López, G. (2011). Image processing applied to classification of avocado variety Hass (Persea americana Mill) during the ripening processariety Hass. Food and Bioprocess Technology, 4(7), 1307-1313. http://dx.doi.org/10.1007/ s11947-011-0595-6.

Benítez, E. I., Amezaga, N. M. J. M., Sosa, G. L., Peruchena, N. M., \& Lozano, J. E. (2013). Turbidimetric behavior of colloidal particles in beer before filtration process. Food and Bioprocess Technology, 6(4), 1082-1090. http://dx.doi.org/10.1007/s11947-012-0905-7.

Benítez, E., Lozano, J., \& Genovese, D. (2010). Fractal dimension and mechanism of aggregation of apple juice particles. Food Science \& Technology International, 16(2), 179-186. http://dx.doi. org/10.1177/1082013209353240. PMid:21339133.

Bianchi, F., \& Bonetto, R. (2001). FERImage: an interactive program for fractal dimension, $\mathrm{d}$ (per) and $\mathrm{d}(\mathrm{min})$ calculation. Scanning, 23(3), 193-197. http://dx.doi.org/10.1002/sca.4950230305. PMid:11405304.

Chen, Z., Liu, Y., \& Zhou, P. (2018). A comparative study of fractal dimension calculation methods for rough surface profiles. Chaos, Solitons, and Fractals, 112, 24-30. http://dx.doi.org/10.1016/j. chaos.2018.04.027.

Choi, S. J., Woo, H. D., Ko, S. H., \& Moon, T. W. (2008). Confocal laser scanning microscopy to investigate the effect of cooking and sodium bisulfite on in vitro digestibility of waxy sorghum flour. Cereal Chemistry, 85(1), 65-69. http://dx.doi.org/10.1094/ CCHEM-85-1-0065.

Dayakar Rao, B., Anis, M., Kalpana, K., Sunooj, K. V., Patil, J. V., \& Ganesh, T. (2016). Influence of milling methods and particle size on hydration properties of sorghum flour and quality of sorghum biscuits. Lebensmittel-Wissenschaft + Technologie, 67, 8-13. http:// dx.doi.org/10.1016/j.lwt.2015.11.033.

Di Rienzo, J. A., Casanoves, F., Balzarini, M. G., Gonzalez, L., \& Tablada, M. R. C. W. (2008). InfoStat, versión 2008. Argentina: Grupo InfoStat/ FCA/Universidad Nacional de Córdoba.

Duodu, K. G., Nunes, A., Delgadillo, I., Parker, M. L., Mills, E. N. C., Belton, P. S., \& Taylor, J. R. N. (2002). Effect of grain structure and cooking on sorghum and maize in vitro protein digestibility. Journal of Cereal Science, 35(2), 161-174. http://dx.doi.org/10.1006/ jcrs.2001.0411.

Girard, A. L., \& Awika, J. M. (2018). Sorghum polyphenols and other bioactive components as functional and health promoting food ingredients. Journal of Cereal Science, 84, 112-124. http://dx.doi. org/10.1016/j.jcs.2018.10.009.

Köylü, O., Xing, Y., Rosner, D. (1995). Fractal morphology analysis of combustion-generated aggregates using angular light scattering and electron microscope images. Langmuir, 11(12), 4848-4854. https:// doi.org/10.1021/la00012a043.
Liu, Ch., Li, L., Hong, J., Zheng, X., Bian, K., Sun, Y., \& Zhang, J. (2014). Effect of mechanically damaged starch on wheat flour, noodle and steamed bread making quality. International Journal of Food Science \& Technology, 49(1), 253-260. http://dx.doi.org/10.1111/ijfs.12306.

Mahasukhonthachat, K., Sopade, P. A., \& Gidley, M. J. (2010). Kinetics of starch digestion in sorghum as affected by particle size. Journal of Food Engineering, 96(1), 18-28. http://dx.doi.org/10.1016/j. jfoodeng.2009.06.051.

Martínez Amezaga, N. M. J., Lataza Rovaletti, M. M. L., \& Benítez, E. I. (2018). Particle size distribution of polysaccharides in beer before the filtration process. International Journal of Food Research, 5, 13-19.

Mercedes Lataza Rovaletti, M., Benítez, E. I., Martinez Amezaga, N. M. J., Peruchena, N. M., Sosa, G. L., \& Lozano, J. E. Lataza Rovaletti, M. M., Benítez, E. I., Martinez Amezaga, N. M. J., Peruchena, N. M., Sosa, G. L., \& Lozano, J. E. (2014). Polysaccharides influence on the interaction between tannic acid and haze active proteins in beer. Food Research International, 62, 779-785. http://dx.doi. org/10.1016/j.foodres.2014.03.017.

Nagai, T., \& Yano, T. (1990). Fractal structure of deformed potato starch and its sorption characteristics. Journal of Food Science, 55(5), 1334-1337. http://dx.doi.org/10.1111/j.1365-2621.1990.tb03929.x.

Nayak, S. R., Mishra, J., \& Palai, G. (2019). Analysing roughness of surface through fractal dimension: a review. Image and Vision Computing, 89, 21-34. http://dx.doi.org/10.1016/j.imavis.2019.06.015.

Pontieri, P., Mamone, G., De Caro, S., Tuinstra, M. R., Roemer, E., Okot, J., De Vita, P., Ficco, D. B., Alifano, P., Pignone, D., Massardo, D. R., \& Del Giudice, L. (2013). Sorghum, a healthy and gluten-free food for celiac patients as demonstrated by genome, biochemical, and immunochemical analyses. Journal of Agricultural and Food Chemistry, 61(10), 2565-2571. http://dx.doi.org/10.1021/jf304882k. PMid:23432128.

Shahzad, S., Hussain, S., Mohamed, A., Alamri, M., Qasem, A., Ibraheem, M. A., Almaimam, S. A. M., \& El-Din, M. F. S. (2018). Gluten-free cookies from sorghum and Turkish beans; effect of some nonconventional and commercial hydrocolloids on their technological and sensory attributes. Food Science and Technology (Campinas), 41(1), 15-24. http://dx.doi.org/10.1590/fst.25419.

Siliveru, K., Kwek, J., Lau, G., \& Ambrose, R. (2016). Image analysis approach to understand the differences in flour particle surface and shape characteristics. Cereal Chemistry Journal, 93(3), 234-241. https://doi.org/10.1094/CCHEM-05-15-0108-R.

Sorensen, C. M., \& Hageman, W. B. (2001). Two-dimensional soot. Langmuir, 17(18), 5431-5434. http://dx.doi.org/10.1021/la0104065.

Szerakowska, S., Woronko, B., Sulewska, M. J., \& Oczeretko, E. (2018). Spectral method as a tool to examine microtextures of quartz sandsized grains. Micron (Oxford, England : 1993), 110, 36-45. http:// dx.doi.org/10.1016/j.micron.2018.04.008. PMid:29727775.

Tang, H. P., Zhu, J. L., Xi, Z. P., Di, X. B., Wang, J. Y., \& Ao, Q. B. (2010). Impact factors of fractal analysis of porous structure. Science China. Technological Sciences, 53(2), 348-351. http://dx.doi.org/10.1007/ s11431-009-0361-4.

Zhu, F. (2014). Structure, physicochemical properties, modifications and uses of sorghum starch. Comprehensive Reviews in Food Science and Food Safety, 13(4), 597-610. http://dx.doi.org/10.1111/15414337.12070. PMid:33412707. 